Jurnal Pemberdayaan: Publikasi Hasil Pengabdian kepada Masyarakat

Vol. 3, No. 2, Agustus 2019, Hal. 245-250

ISSN: 2580-2569; e-ISSN: 2656-0542

DOI: https://doi.org/10.12928/jp.v3i2.1120

\title{
Pelatihan pembuatan teh celup pegagan Centella asiatica (L) Urban) di Desa Nglanggeran
}

\author{
Iis Wahyuningsih, Nazilah Shofi Risqina \\ Universitas Ahmad Dahlan, Jl. Prof. Dr. Supomo, Janturan, Yogyakarta \\ Email: iis.wahyuningsih@pharm.uad.ac.id
}

\begin{abstract}
ABSTRAK
Desa Nglanggeran, Patuk, Gunungkidul mempunyai banyak potensi sumber daya alam, salah satunya banyak tumbuh tanaman pegagan. Namun masyarakat, khususnya ibu-ibu PKK belum mempunyai pengetahuan dan ketrampilan membuat teh pegagan. Pengabdian kepada masyarakat ini bertujuan untuk: (1) memberi penyuluhan tentang tanaman pegagan dan khasiatnya; (2) melatih keterampilan membuat teh celup pegagan; (3) melatih mengemas teh pegagan; (4) melatih membuat label pada kemasan teh pegagan. Metode yang digunakan adalah pelatihan dan praktek langsung. Tim pelaksana program terdiri dari dosen Fakultas Farmasi UAD dan mahasiswa Prodi S2 Farmasi UAD. Pelaksanaan kegiatan diselenggarakan di balai Desa Nglanggeran, Kecamatan Patuk, Gunungkidul. Hasil dari pelaksanaan pengabdian kepada masyarakat adalah peningkatkan pengetahuan tentang tanaman pegagan, peserta terampil membuat teh pegagan, peserta terampil mengemas teh pegagan, peserta terampil melabel teh pegagan. Program yang telah dilaksanakan tersebut memberikan dampak positif bagi peserta yang dapat dilihat dari peningkatan pengetahuan dan keterampilan ibu-ibu PKK desa Nglanggeran.
\end{abstract}

Kata kunci: pegagan, teh celup, pelatihan, PKK

\begin{abstract}
Nglanggeran, Patuk, Gunungkidul have a lot of potential natural resources, one of them is a "pegagan" plant which lives a lot there. But the community, especially the PKK members do not have the knowledge and the skills to make "pegagan" tea. Community service aims to: (1) give counseling about "pegagan" plants and their efficacy; (2) practice the skill of making "pegagan" tea bag; (3) train packing "pegagan" tea; (4) practice making labels on teh "pegagan" packaging. The method used are direct training and practice. The program implementation team consisted of lecturers from the Faculty of Pharmacy of UAD and UAD Master of Pharmacy students. The activity was held in the village of Nglanggeran, Patuk District, Gunungkidul. The results of these community service are enhancements knowledge of "pegagan" plants, participants have skilled making "pegagan" tea, skilled packaging teh pegagan tea, skilled at labeling teh "pegagan" tea. These community service program has a positive impact on participants which can be seen from the improvement knowledge and skills of PKK members.
\end{abstract}

Keywords: pegagan, tea, practice 


\section{PENDAHULUAN}

Pegagan adalah salah satu tanaman yang tumbuh liar di lingkungan Desa Nglanggeran dan belum dimanfaatkan masyarakat. Pegagan merupakan tanaman liar yang merambat di tanah dan biasa hidup di sepanjang jalan. Beberapa penelitian sudah membuktikan tanaman pegagan memiliki manfaat yang besar beberapa diantaranya adalah antialergi, antigatal dan antiinflamasi (Somchit, et al, 2004; George et al., 2009). Aktivitas antiinflamasi dari ekstrak air herba pegagan dapat dikaitkan dengan adanya glikosida seperti asiaticoside dan madecassoside (George et al., 2009). Salah satu zat aktif dari ekstrak air herba pegagan yaitu saponin jenis asiaticoside dan madecassoside yang memiliki aktifitas sebagai antiinflamasi (Zheng dan Qin, 2007; James and Dubery, 2009). Pegagan memiliki berbagai kandungan kimia yaitu asiaticoside, thankuniside, isothankuniside, madecassoside, brahmoside, brahmic acid,brahminoside, madasiatic acid, meso-inositol, centelloside, carotenoids, hydrocotylin, vellarine, tannin serta garam mineral seperti kalium, natrium, magnesium, kalsium dan besi, (George et al., 2009), sehingga berpotensi untuk dikembangkan menjadi minuman kesehatan.

Teh celup adalah sebutan untuk serbuk bunga, daun, biji, akar, atau buah kering yang dicelupkan/diseduh dalam air panas untuk membuat minuman. Walaupun disebut "teh", ramuan atau minuman ini tidak selalu mengandung daun dari tanaman teh (Camellia sinensis). Pengembangan potensi pegagan dipilih menjadi sediaan celup, sebab keuntungan metode pembuatan sediaan celup yang sederhana, murah, dan praktis. Hal ini juga menarik dan unik karena teh ini bukan terbuat dari daun teh melainkan tanaman pegagan.

PKK adalah salah satu organisasi masyarakat yang anggotanya adalah ibu-ibu. Organisasi ini berperan penting dalam masyarakat terutama bagi ibu-ibu berbagi informasi seputar kehidupan sehari-harinya. Organisasi PKK merupakan target yang tepat untuk pelaksanaan program pencegahan maupun pengobatan di desa Nglanggeran. Pemanfaatan tanaman secara langsung kurang praktis sehingga perlu dibuat dalam sediiaan yang mudah untuk digunakan seperti sediaan teh celup Dengan meningkatnya pengetahuan ibu-ibu PKK terkait teh celup pegagan maka kedepannya diharapkan dapat membuat produk teh pegagan sendiri maupun untuk dijual. Berdasarkan uraian di atas maka tujuan dari kegiatan ini adalah mensosialisasi tanaman pegagan dan manfaatnya, cara membuat teh celup, mengemas dan melabel produk.

\section{METODE}

Kegiatan pengabdian kepada masyarakat ini menggunakan metode penyuluhan dan praktek langsung. Mitra sasaran adalah ibu-ibu PKK desa Nglanggeran, Patuk, Gunungkidul. Subjek sasarannya berjumlah 15 orang dari perwakilan ibu-ibu PKK desa Nglanggeran. Program pelatihan dilakukan dengan tahapan : persiapan, pelaksanaan dan evaluasi. Kegiatan ini diselenggarakan pada tanggal 14-17 Mei 2019. Kegiatan pelatihan ini dilaksanakan oleh dosen farmasi yang mempunyai kompetensi pada pembuatan sediaan dari tanaman herbal. Disamping dosen, kegiatan ini juga melibatkan 1 mahasiswa S2 Farmasi. Kegiatan pelatihan diselenggarakan di balai Desa Nganggeran, Patuk, Gunungkidul.

\section{HASIL, PEMBAHASAN, DAN DAMPAK}

Pelatihan dimulai dengan penyampaian materi dengan media PPT, agar mudah dipahami oleh ibu-ibu PKK. Kegiatan presentasi dilakukan untuk menambah pemahaman peserta sebelum masuk pada kegitan praktek pembuatan sediaan teh pegagan celup. Kegiatan ini juga memberi kesempatan kepada peserta untuk bertanya. Selanjutnya kegiatan diteruskan dengan praktek pembuatan serbuk daun pegagan. Kegiatan pelatihan ini dipilih karena dari hasil 
pengamatan dapat mengembangkan potensi tanaman pegagan. Pengembangan potensi pegagan dipilih menjadi sediaan celup, sebab keuntungan metode pembuatan sediaan celup yang sederhana, murah, dan praktis. Hal ini juga menarik dan unik karena teh ini bukan terbuat dari daun teh melainkan tanaman pegagan. Tahapan yang dipraktekkan peserta selanjutnya adalah membuat kantong teh celup. Kertas teh celup yang digunakan masih dalam bentuk gulungan, sehingga diperlukan proses pengukuran, pemotongan dan pengepresan.

Setelah kantong saring teh selesai dibuat, proses selanjutnya adalah memasukkan serbuk pegagan kering sesuai takaran yang telah ditentukan dan kantong teh ditutup dengan alat sealer. Serbuk pegagan yang telah dikemas dengan kantong teh celup selanjutnya dimasukkan dalam kemasan alumunium foil yang telah dibuat sebelumnya. Tujuannya agar sediaan celup dapat bertahan lebih lama. Tahap terakhir dilakukan dengan memberi label pada kemasan aluminium foil yang telah terisi teh pegagan celup. Pelatihan pembuatan sediaan teh celup pegagan ditutup dengan penyeduhan celup pegagan secara bersama-sama, untuk meyakinkan peserta bahwa sediaan celup pegagan mempunyai cita rasa yang dapat diterima. Gambaran tahapan pembuatan teh celup pegagan tersaji pada gambar 1 .

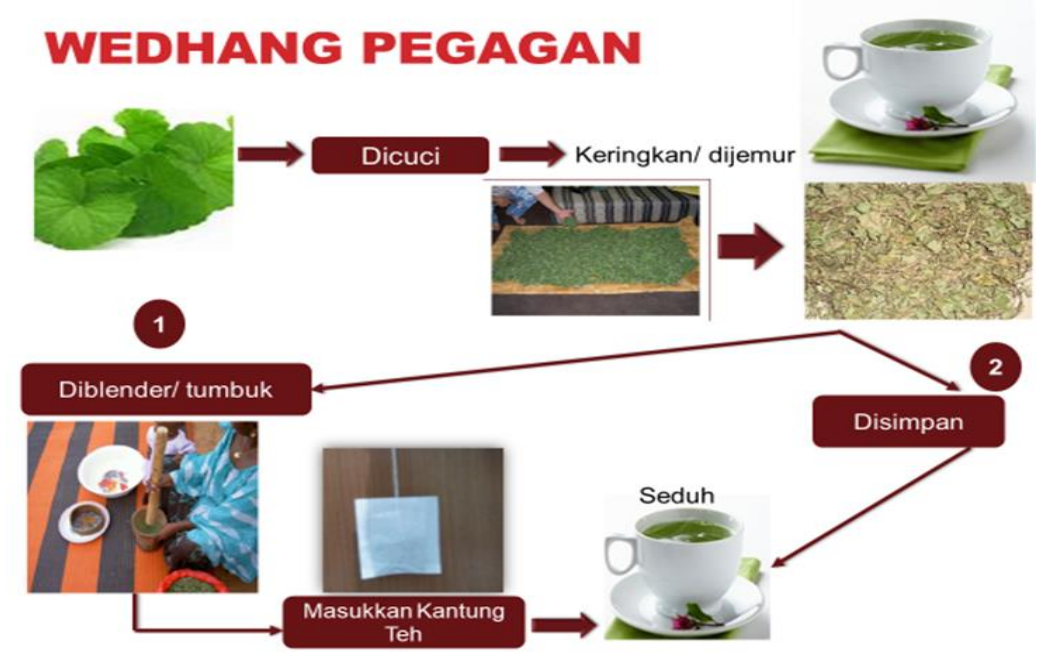

Gambar 1. Tahapan proses pembuatan teh celup pegagan

Gambaran kegiatan tersaji pada Gambar 2.

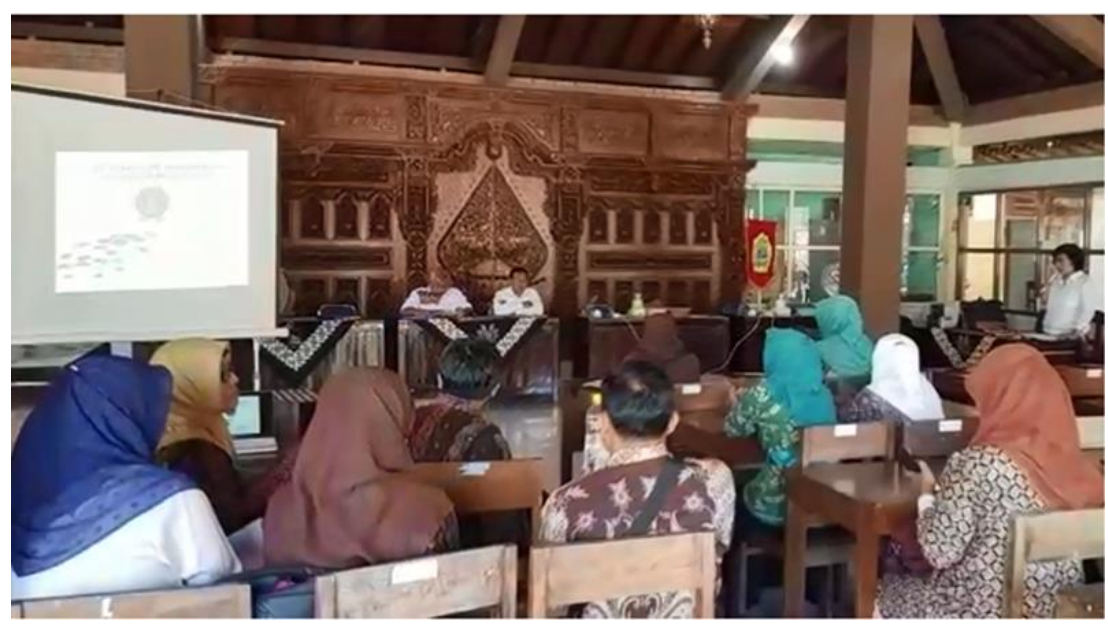

Gambar 2. Pembukaan kegiatan pelatihan pembuatan teh celup pegagan dilakukan oleh Camat Patuk. 
Evaluasi untuk kegiatan ini digunakan media post test untuk mengevaluasi hasil pre test yang telah dilakukan. Hasil nilai pre test dan post test kegiatan pelatihan dapat dilihat pada Gambar 3.

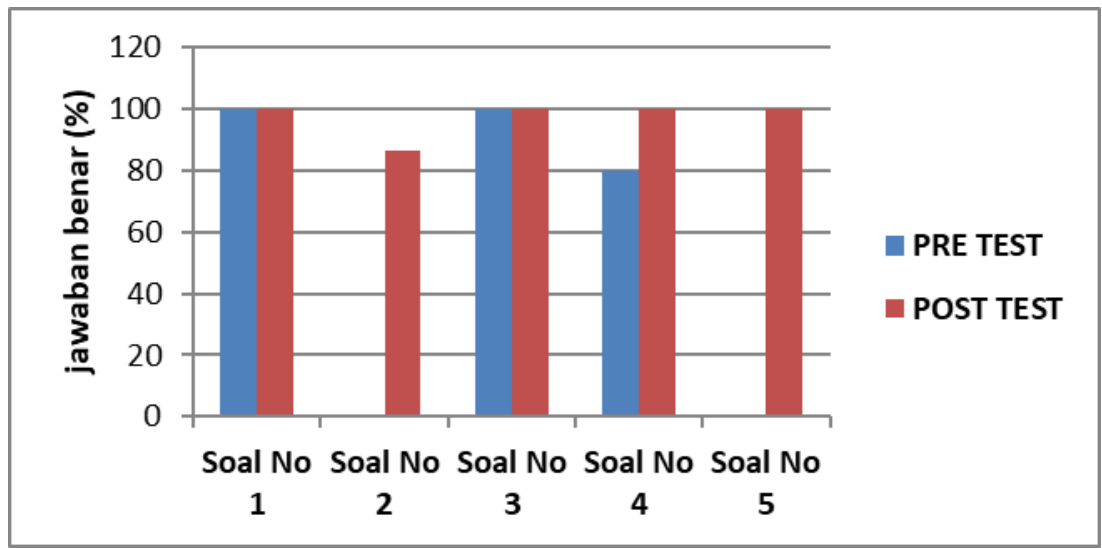

Gambar 3. Hasil pre test dan post test pengetahuan peserta terkait pembuatan teh celup pegagan

Dari gambar 3 nomor soal 1 terlihat, 100\% peserta sudah mengenal tanaman pegagan. Namun, pada soal nomor 2 terlihat peserta belum mengenal dengan baik khasiat dari tanaman pegagan. Pada gambar 3 soal nomor 3 menunjukkan peserta sudah mengetahui bagian mana dari tanaman pegagan yang sering dimanfaatkan. Pada soal nomor 4 terjadi peningkatan pengetahuan $20 \%$ tentang persyaratan hygienitas sebelum membuat teh celup pegagan. Terjadi peningkatan $100 \%$ pengetahuan peserta tentang kandungan dari tanaman pegagan. Secara keseluruhan program yang telah dilaksanakan memberikan dampak positif bagi peserta yang dapat dilihat dari peningkatan pengetahuan dan keterampilan ibu-ibu PKK desa Nglanggeran tentang tahapan membuat teh celup pegagan.

\section{SIMPULAN}

Tahapan kegiatan pelatihan teh celup pegagan untuk ibu-ibu PKK Nganggeran, Patuk, Gunungkidul dapat diselenggarakan dengan baik. Melalui pelatihan yang diberikan mampu meningkatkan pengetahuan dan ketrampilan peserta tentang tanaman pegagan dan pembuatan teh celup pegagan.

\section{UCAPAN TERIMAKASIH}

Terimakasih kepada LPPM Universitas Ahmad Dahlan dan Camat Patuk.

\section{DAFTAR PUSTAKA}

George, Joseph, Ramaswamy. (2009). Anti Allergic, Anti Pruritic, and Anti Inflammatory Activities of Centella asiatica Extracts. Afr. J. Trad., 6(4): 554-559

James, and Dubery, (2009), Pentacyclic Triterpenoids from the Medicinal Herb Centella asiatica (L.) Urban. Molecules, 14: 3922-3941. 
Somchit, Sulaiman, Zuraini, Samsuddin, Somchit, Israf, Moin, (2004), Antinociceptive and Antiinflammatory Effects of Centella asiatica. Indian J. Pharmacol, 36(6):377-380.

Zheng, Qin, (2007), Chemical Components of Centella asiatica and Their Bioactivities. J Chin Integr Med, 5(3): 348-351. 
